\title{
Combined cell surface carbonic anhydrase 9 and CD147 antigens enable high-efficiency capture of circulating tumor cells in clear cell renal cell carcinoma patients
}

\author{
Shijie Liu ${ }^{1,2, *}$, Zuhong Tian ${ }^{2, *}$, Lei Zhang ${ }^{3, *}$, Shuang Hou ${ }^{4}$, Sijun $\mathrm{Hu}^{2}$, Junshen $\mathrm{Wu}^{1}$, \\ Yuming Jing ${ }^{1}$, Huimin Sun ${ }^{1}$, Fei $\mathbf{Y u}^{1}$, Libo Zhao ${ }^{5}$, Ruoxiang Wang ${ }^{6}$, Hsian-Rong \\ Tseng $^{4}$, Haiyen E. Zhau ${ }^{6}$, Leland W.K. Chung ${ }^{6}$, Kaichun Wu ${ }^{2}$, Hao Wang ${ }^{7}$ Jason \\ Boyang Wu${ }^{8}$, Yongzhan $\mathrm{Nie}^{2}$, Chen Shao ${ }^{1,2}$ \\ ${ }^{1}$ Department of Urology, Xijing Hospital, The Fourth Military Medical University, Xi'an, Shaanxi 710032, China \\ ${ }^{2}$ State Key Laboratory of Cancer Biology \& Xijing Hospital of Digestive Diseases, The Fourth Military Medical University, Xi'an, \\ Shaanxi 710032, China \\ ${ }^{3}$ Department of Epidemiology, The Fourth Military Medical University, Xi'an, Shaanxi 710032, China \\ ${ }^{4}$ Department of Molecular and Medical Pharmacology, Crump Institute for Molecular Imaging, California Nanosystems \\ Institute, University of California, Los Angeles, CA 90095, USA \\ ${ }^{5}$ Beijing National Laboratory for Molecular Sciences, Key Laboratory of Molecular Nanostructure and Nanotechnology, \\ Institute of Chemistry, Chinese Academy of Sciences, Beijing 100190, China \\ ${ }^{6}$ Uro-Oncology Research Program, Department of Medicine, Samuel Oschin Comprehensive Cancer Institute, Cedars-Sinai \\ Medical Center, Los Angeles, CA 90048, USA \\ ${ }^{7}$ CAS Key Laboratory for Biological Effects of Nanomaterials and Nanosafety, National Center for Nanoscience and \\ Nanotechnology, Beijing 100190, China \\ ${ }^{8}$ Department of Pharmaceutical Sciences, College of Pharmacy, Washington State University, Spokane, WA 99202, USA \\ * These authors have contributed equally to this work \\ Correspondence to: Hao Wang, email: wanghao@nanoctr.cn \\ Jason Boyang Wu, email: boyang.wu@wsu.edu \\ Yongzhan Nie, email: yongznie@fmmu.edu.cn \\ Chen Shao, email: shaochen@fmmu.edu.cn
}

Keywords: carbonic anhydrase 9, CD 147, circulating tumor cells, renal cell carcinoma

Received: January 10, $2016 \quad$ Accepted: July 18, $2016 \quad$ Published: August 1, 2016

\section{ABSTRACT}

Circulating tumor cells (CTCs) have emerged as promising tools for noninvasive cancer detection and prognosis. Most conventional approaches for capturing CTCs use an EpCAM-based enrichment strategy, which does not work well in cancers that show low or no expression of EpCAM, such as renal cell carcinoma (RCC). In this study, we developed a new set of cell surface markers including CA9 and CD147 as alternative CTC-capture antigens specifically designed for RCC patients. We showed that the expression of both CA9 and CD147 was prevalent in a RCC patient cohort $(n=70)$ by immunohistochemical analysis, with both molecules in combination covering $97.1 \%$ of cases. The NanoVelcro platform combined with CA9-/CD147-capture antibodies demonstrated significantly higher efficiency for capturing both CTC-mimicking renal cancer cells and RCC CTCs in peripheral blood, compared to the conventional EPCAMbased method. Using immunofluorescence cytological validation at the single-cell level, we were able to identify bona fide CTCs in RCC patient blood following the wellaccepted criteria in our CTC-capture system. We further demonstrated a significant association of CTC numbers as well as the CTC expression status of Vimentin, a mesenchymal marker, with disease progression, including pathologic features and clinical staging. These results provide new insights into developing novel, effective targets/approaches for capturing CTCs, making CTCs a valuable tool for improved cancer detection, prognosis and treatment in RCC. 


\section{INTRODUCTION}

Circulating tumor cells (CTCs) are cancer cells that invade blood circulation, eventually leading to systemic dissemination at distant sites [1]. Understanding the biological nature of CTCs is the key to the diagnosis, prognosis and treatment of cancer metastasis. Recently, the clinical relevance of CTCs in metastatic cancers has been clearly demonstrated in multiple types of advanced cancer including breast cancer, prostate cancer and colon cancer, where CTC detection has been significantly enhanced by the development of EpCAM-based enrichment strategies [2-4].

The epithelial cell adhesion molecule (EpCAM), a cell surface glycoprotein highly expressed in epithelial cancer cells, currently serves as the major capture antigen for CTC detection [5, 6]. However, EpCAM is only partially expressed in certain types of cancers, leading to inefficient capture and the escape of CTCs from EpCAMbased detection, which is further exacerbated by the fact of tumor heterogeneity [7, 8]. In addition, the use of EpCAM-based enrichment techniques likely leads to the failure to detect CTC populations that have undergone epithelial-mesenchymal transition (EMT), with the loss of more epithelium-like CTCs $[9,10]$. The limitations of EpCAM-based capture methods indicate the urgent need to develop alternative cancer type-specific capture antigens for improved capture of CTCs.

In recent decades, the incidence of renal cell carcinoma (RCC) has risen steadily; kidney cancer, with the vast majority being RCC, was the $7^{\text {th }}$ leading cancer type in men in the Unites States in 2015 [11]. Successful management of RCC patients, particularly those with recurrent and metastatic RCC, largely relies on early detection and prognosis of disease progression. The noninvasive detection of CTCs in peripheral blood of patients has become a useful clinical tool in other cancers, such as breast cancer [12], but the conventional CTC-capture marker EpCAM is only expressed in 30$40 \%$ of RCC and thus is not an ideal capture antigen for the detection of CTCs in RCC patients [13]. Although other biomarkers, including $\mathrm{p} 53, \mathrm{p} 21$, HIF-1 $\alpha$, caveolin-1 and survivin, have been reported as potential prognostic biomarkers for RCC patients [14, 15], these markers are not located on the cell membrane. Therefore, improving the efficiency of CTC capture in RCC patients by developing alternative cell surface biomarkers remains a challenge.

By immunohistochemical (IHC) analysis of clinical RCC specimens, we recently found two surface biomarkers, carbonic anhydrase 9 (CA9) and CD147, which show excellent features as candidate capture antigens for RCC CTCs. CA9, a transmembrane member of the carbonic anhydrase family, is not expressed in healthy and benign renal tissues, but it is present in $91.2 \%$ of clear cell renal cell carcinomas (CCRCC), which make up $75 \%$ of RCC, by IHC analysis [16, 17]. CD147, a highly glycosylated member of the immunoglobulin superfamily expressed on the surface of many malignant tumors, such as ovarian cancer and bladder cancer [18$20]$, is also positively expressed in up to $88.7 \%$ of patients with advanced RCC [21]. In addition, recent studies using multiple antigens to capture CTCs suggest the possibility of using CA9 and CD147 together for more effective and sensitive capture of CTCs compared to use of a single molecule for RCC diagnostics and prognostics [22-25]. In this study, we demonstrated the use of CA9 and CD147 in combination as effective antigens for capturing CTCs in RCC patients with higher efficacy and sensitivity than the conventional EpCAM-based detection, suggesting the translational potential of our method for future development of CTC detection technologies for clinical applications to benefit RCC patients.

\section{RESULTS}

\section{Validation of CTC-capture antigens}

In this study, we used the NanoVelcro System, a nanostructured platform, to capture CTCs from $2 \mathrm{ml}$ peripheral blood of each patient in a cohort including 76 RCC patients, 10 benign renal patients and 15 healthy volunteers (Table 1). The isolated CTCs were subsequently subjected to pathologic identification and cellular characterization. Owing to the advantages of its topographic interaction effect, this CTC-capture platform has been successfully used for the enrichment of CTCs in different types of cancer [26-29]. Given that clear cell renal cell carcinoma (CCRCC) is the dominant form accounting for about $75 \%$ of all RCCs [16], we focused on this specific RCC subtype in the present study.

We first evaluated the simultaneous expression of EpCAM, CA9 and CD147 in serial sections of tumor specimens collected from the RCC patient cohort spanning 4 different clinical stages by IHC analysis. EpCAM was only positively expressed in $18.6 \%$ of cases with a range of $6.3-27.6 \%$ in each clinical stage, and there was a declining trend of EpCAM positivity in patients with advancedstage RCC (III and IV) compared to early-stage cases (I and II) (Figure 1A and Table 2). By contrast, CA9 and CD147 showed prevalent expression in $88.6 \%$ and $82.9 \%$ of cases, respectively (Table 2). Moreover, CA9 had a slightly higher rate of positive expression in early-stage (I and II) relative to advanced-stage (III and IV) cases, whereas CD147 was more positively expressed in stage III and IV cases than those with stages I and II (Figure 1A and Table 2). Therefore, CA9 and CD147 in combination complement each other and cover the entire cohort to a greater extent than either antigen alone. Indeed, 97.1\% of cases showed positive expression of CA9, CD147 or both, with a range of $93.8-100 \%$ in each clinical stage (Figure 1A and Table 2). Notably, we showed positive 
Table 1: Characterization of 86 patients (renal cell carcinoma, $n=76$; benign, $n=10$ ) and 15 healthy volunteers registered in the CTC enumeration study

\begin{tabular}{lc}
\hline Subject category & $\mathbf{n}$ \\
\hline Volunteer & 15 \\
Benign & 10 \\
Renal cell carcinoma (RCC) & 76 \\
Subject gender & Age, median (range) \\
Total & $56(16-78)$ \\
Men & $53(69.7)$ \\
Women & $23(32.8)$ \\
RCC subtype & $\mathbf{n}(\mathbf{\%})$ \\
Clear cell renal cell carcinoma & $76(100 \%)$ \\
Stage & $\mathbf{n}(\mathbf{\%})$ \\
I & $29(38.2 \%)$ \\
II & $19(25.0 \%)$ \\
III & $16(21.1 \%)$ \\
IV & $12(15.8 \%)$ \\
Tumor location & $\mathbf{n}(\mathbf{\%})$ \\
Left kidney & $36(47.4 \%)$ \\
Right kidney & $40(52.6 \%)$ \\
\hline
\end{tabular}

expression of CA9 and/or CD147 in 96.4\% of EpCAM cases as well as $100 \%$ of $\mathrm{EpCAM}^{+}$cases (Figure $1 \mathrm{C}$ and Table 2). We also analyzed the parallel IHC expression of CA9, CD147 and EpCAM by a semi-quantitative method by taking into account both quantity of proportion of cells stained and staining intensity. Consistently, CA9 and CD147 demonstrated significantly higher IHC scores than EpCAM across all stages (Figure 1B), with the majority of IHC scores distributed in an EpCAM-independent manner in each stage (Figure 1D). In addition, as revealed by IHC staining, all three markers were expressed in tumor cell membrane with no expression in other types of cells, such as stromal cells, in the same areas (Figure 1E). These observations in aggregate suggest the potential of using CA9 and CD147 in combination as capture antigens to replace EpCAM for capturing CTCs with higher enrichment efficiency.

\section{Optimization of the NanoVelcro capture platform}

To optimize the working conditions of the NanoVelcro platform, we tested the capture efficiency at different flow rates (i.e. $0.1,0.2,0.5,1$ and $2 \mathrm{~mL} / \mathrm{h}$ ). As shown in Figure 2A, the highest capture efficiency was obtained at $0.5 \mathrm{~mL} / \mathrm{h}$, which was selected for subsequent capture of CTCs in patient blood. We also assessed the cell distribution on the channels of patterned silicon nanowire substrate, and the majority of captured cells were found in the first 10 channels among all 11 channels structured in the chip (Figure 2B). Finally, we spiked serial numbers of cultured renal cancer cells in saline to mimic the circulation of CTCs in blood, and demonstrated that the NanoVelcro system was capable of capturing these CTCmimicking cells in a cell number-dependent linear manner $\left(\mathrm{R}^{2}=0.9988\right.$, Figure $\left.2 \mathrm{C}\right)$. Together, these studies optimized the CTC-capture conditions of the NanoVelcro platform in the present system, allowing a steady and reliable collection of CTCs in clinical scenarios.

\section{Combined CA9-/CD147-based capture of renal cancer cells and CTCs}

To examine the renal CTC-capture efficiency of using CA9 and CD147 as capture antigens, we first used the NanoVelcro platform to capture renal cancer cells from two representative human CCRCC lines, Caki-1 and Caki2. Compared to the EpCAM-based enrichment approach, the combined use of CA9 and CD147 in parallel allowed the capture of both Caki-1 $(p<0.01)$ and Caki-2 $(p<0.05)$ cells with higher efficiency (Figure 3A). Next, we compared the efficiency of capturing clinical RCC CTCs 

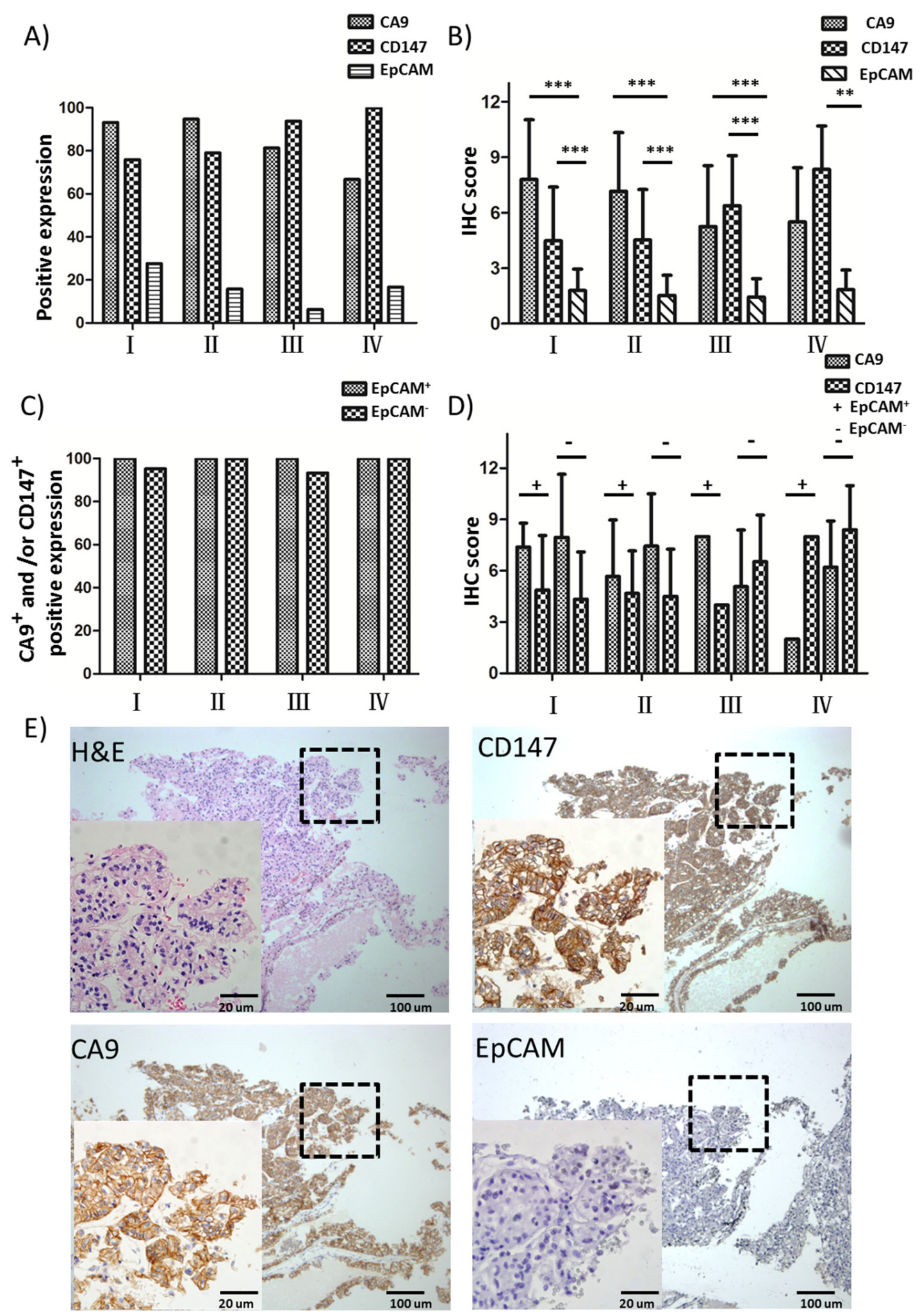

Figure 1: IHC analysis of EpCAM, CA9 and CD147 expression in RCC patient cohort. A. Positive expression percentages of EpCAM, CA9 and CD147 in RCC patient samples of different clinical stages by IHC analysis (I, n=29; II, n=19; III, n=16; IV, n=6). B. IHC scores of EpCAM, CA9 and CD147 in RCC samples of (A). *** $p<0.001$. C. Positive expression percentages of CA9 ${ }^{+}$and/or $\mathrm{CD}_{147^{+}}$in $\operatorname{EpCAM}^{+}$(I, n=8; II, n=3; III, n=1; IV, n=1) or EpCAM- (I, n=21; II, n=16; III, n=15; IV, n=5) RCC patient samples of different clinical stages by IHC analysis. D. IHC scores of EpCAM, CA9 and CD147 in RCC samples of (C). E. H\&E and IHC staining of EpCAM, CA9 and CD147 in representative EpCAM- RCC patient tissues. The selected enlarged areas are indicated in dashed rectangles. Original magnification, $400 \times$ (enlarged) and $100 \times$ (original); scale bars: $20 \mu \mathrm{m}$ (enlarged) and $100 \mu \mathrm{m}$ (original). 
Table 2: Distribution of positive expression of EpCAM, CA9 and CD147 in the RCC patient cohort

\begin{tabular}{|c|c|c|c|c|c|}
\hline & $\mathbf{I}$ & II & III & IV & Total \\
\hline $\mathrm{CA}^{+}$ & $27 / 2993.1 \%$ & $18 / 1994.7 \%$ & $13 / 1681.3 \%$ & $4 / 666.7 \%$ & $62 / 7088.6 \%$ \\
\hline $\mathrm{CD} 147^{+}$ & $22 / 2975.9 \%$ & $15 / 1979.0 \%$ & $15 / 1693.8 \%$ & $6 / 6100 \%$ & $58 / 7082.9 \%$ \\
\hline $\mathrm{EpCAM}^{+}$ & $8 / 2927.6 \%$ & $3 / 1915.8 \%$ & $1 / 166.3 \%$ & $1 / 616.7 \%$ & $13 / 7018.6 \%$ \\
\hline $\mathrm{CA}^{+}$and/or $\mathrm{CD} 147^{+}$ & $28 / 2996.5 \%$ & $19 / 19100 \%$ & $15 / 1693.8 \%$ & $6 / 6100 \%$ & $68 / 7097.1 \%$ \\
\hline $\begin{array}{l}\mathrm{CA}^{+} \text {and/or } \mathrm{CD} 147^{+} \text {in } \\
\mathrm{EpCAM}^{+} \text {group }\end{array}$ & $8 / 8100 \%$ & $3 / 3100 \%$ & $1 / 1100 \%$ & $1 / 1100 \%$ & $13 / 13100 \%$ \\
\hline $\begin{array}{l}\mathrm{CA}^{+} \text {and/or } \mathrm{CD} 147^{+} \text {in } \\
\text { EpCAM }^{-} \text {group }\end{array}$ & $20 / 2195.2 \%$ & $16 / 16100 \%$ & $14 / 1593.3 \%$ & $5 / 5100 \%$ & $55 / 5796.4 \%$ \\
\hline
\end{tabular}

between EpCAM- and CA9-/CD147-based enrichment strategies by the NanoVelcro system. We demonstrated a $181 \%$ increase of capture efficiency of cytologically validated CTCs in $2 \mathrm{~mL}$ blood when CA9 and CD147 were used in combination as capture antigens in comparison with EpCAM antigen $(p<0.001$, Figure 3B), which was consistent with the observations made by IHC in clinical RCC samples. We also confirmed a high percentage of $\mathrm{CA} 9^{+}$and/or $\mathrm{CD} 147^{+}$expression, with an average of $84 \%$, on the cell membrane of CTCs (DAPI $\left.{ }^{+} / \mathrm{CD} 45^{-}\right)$captured by CA9-/CD147-based enrichment approach in 94\% (31 out of 33) samples we examined, which was accompanied by positive staining of CA9 and CD147 in the corresponding RCC samples as revealed by IHC (Figure 4A and Table 3 ). The missing expression of CA9 and/or CD147 in 2 CTC samples (patients 22 and 27) was largely due to their low expression in the corresponding primary tumors where CTCs were considered to shed (Table 3). Although we compared the expression of CA9 and CD147 in isogenic pairs of primary tumors and CTCs from only a portion (33 out of 76) of our cohort due to limited quantities of patient blood we were able to collect for multiple analyses, the prevalent consistency of their expression patterns in these samples spanned 4 different clinical stages and thus, to a great extent, might represent the entire cohort. Collectively, these results support the idea of substituting EpCAM with combined CA9 and CD147 as capture antigens for improved capture efficiency and sensitivity in $\mathrm{RCC}$.

\section{Cytological characterization of CTCs}

To eliminate the potential interference of white blood cells (WBCs) with the captured CTCs, we enumerated and characterized CTCs at the single-cell level by immunofluorescence. We defined cells meeting all the following criteria under microscopy as bona fide CTCs: 1) cellular diameter between $13 \mu \mathrm{m}$ and $50 \mu \mathrm{m}$, 2) positive cytokeratin $(\mathrm{CK})$ expression for epithelial cell staining but negative CD45 expression for WBC staining, and 3) a $>50 \%$ nuclear-cytoplasmic ratio for CTCs in contrast to that less than $30 \%$ for WBCs. We used DAPI, fluorescence-labeled anti-pan-CK and antiCD45 antibodies to visualize nuclei, epithelial cells and WBCs, respectively. In addition to these cellular markers, we further introduced Vimentin, a mesenchymal marker, to characterize the mesenchymal state of captured CTCs, which is in line with emerging studies that demonstrated the ability of CTCs to exhibit dynamic changes in epithelial and mesenchymal composition as well as an association of mesenchymal CTCs with disease progression [30-33]. Following the CTC selection criteria cited above, we identified three different types of cells in the entire pool of captured cells from the patient cohort, including two types of CTCs, $\mathrm{DAPI}^{+} / \mathrm{CK}^{+} / \mathrm{CD} 45 \%$ Vimentin ${ }^{+}$and $\mathrm{DAPI}^{+} / \mathrm{CK}^{+} / \mathrm{CD} 45^{-} /$Vimentin, and $\mathrm{WBCs}$ defined by $\mathrm{DAPI}^{+} / \mathrm{CK}^{-} / \mathrm{CD} 45^{+}$. Of note, we were able to observe all three types of cells in a single patient sample, such as Patient 9, patient 60, patient 69 (Figure 4B). These results demonstrate the capability of the combined CA9-/ CD147-based enrichment method to capture bona fide RCC CTCs from clinical blood samples.

\section{Clinical implications of CTCs in RCC}

To examine whether the CTCs captured by the combined CA9-/CD147-based enrichment approach are clinically relevant, we sought to associate the numbers of cytologically validated CTCs with different clinical indices, including pathologic indication and clinical stage. We were able to detect CTCs in $94.7 \%$ of RCC patients (72/76). As shown in Figure 5A, the number of $\mathrm{DAPI}^{+}$ $\mathrm{CK}^{+} / \mathrm{CD} 45^{-}$CTCs captured in $2 \mathrm{~mL}$ RCC patient blood $(12.8 \pm 6.9, \mathrm{n}=76)$ was significantly higher, with a 7.5fold increase over that obtained from benign patients (1.7 $\pm 1.7, \mathrm{n}=10$ ), including angiomyolipoma, renal adenoma and fibroma. As expected, we did not detect $\mathrm{DAPI}^{+} / \mathrm{CK}^{+} /$ CD45- CTCs in $2 \mathrm{~mL}$ peripheral blood from 13 out of 15 healthy volunteers except 2 donors wherein one or two cells with potential malignancy were captured and 
A)

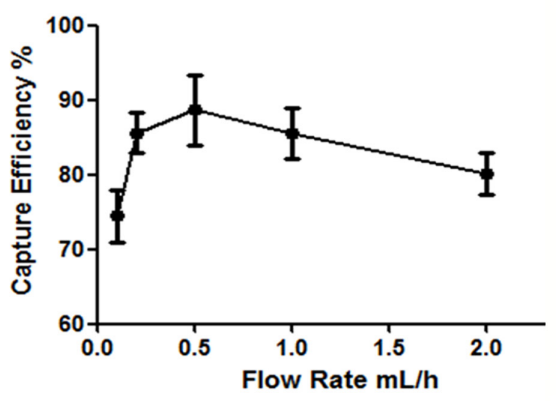

C)

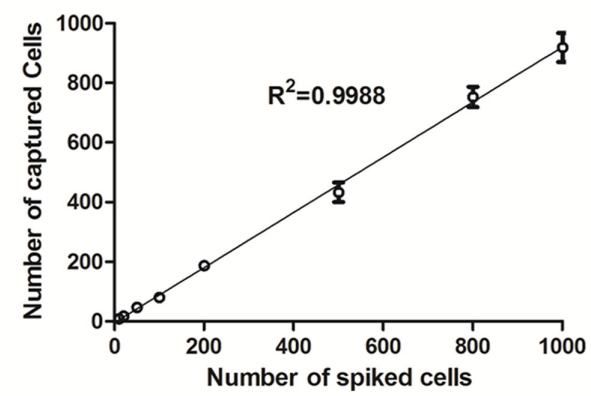

B)

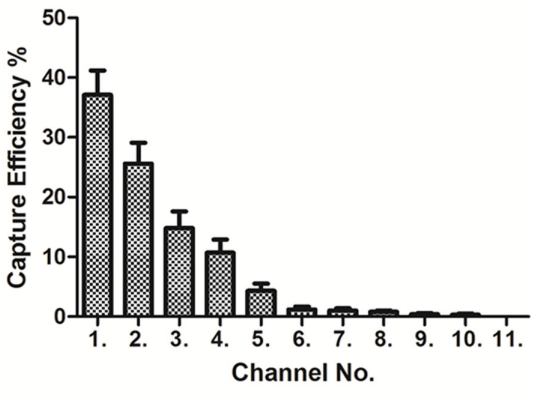

Figure 2: Optimization of the NanoVelcro system. A. Cell-capture efficiency of the NanoVelcro Chip at flow rates of $0.1,0.2,0.5$, 1 , and $2 \mathrm{~mL} / \mathrm{h}$. Data represent the mean $\pm \mathrm{SD}(\mathrm{n}=3)$. B. The cell distribution and accumulative cell-capture efficiency in a NanoVelcro Chip assessed in PBS. C. Cell-capture efficiency with different spiked cell numbers ranging from 10 to $1000 \mathrm{cells} / \mathrm{mL}$ in PBS.

A)

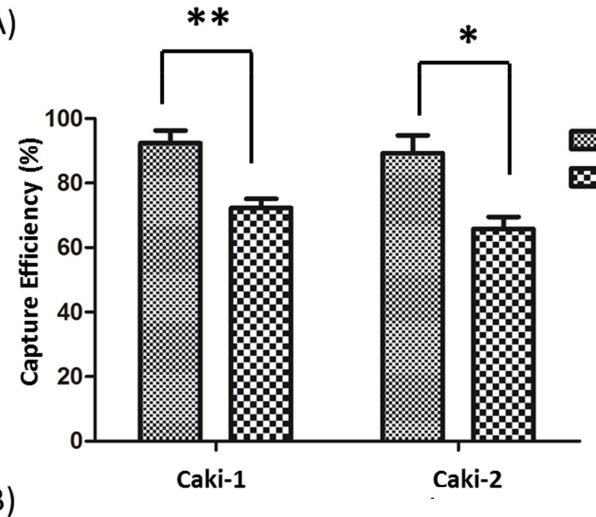

B)

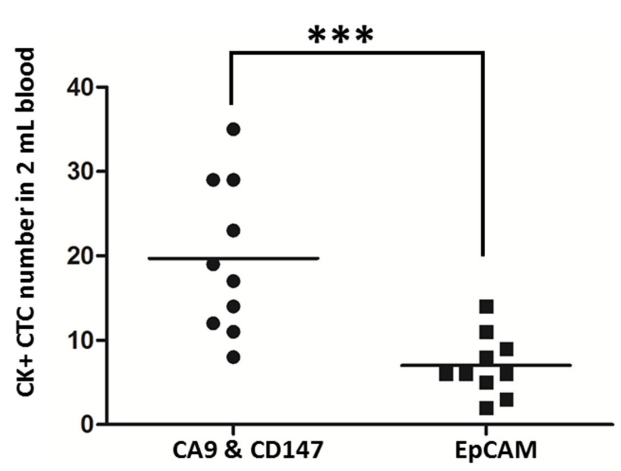

Figure 3: CTC capture by NanoVelcro Chips coupled with combined use of CA9 and CD147 as capture antigens. A., B. Comparisons of capture efficiency between combined CA9-/CD147-based and EpCAM-based NanoVelcro Chips for CTC-mimicking Caki-1/Caki-2 renal cancer cells (A) or CTCs in peripheral blood of 10 RCC patients (B). ${ }^{*} p<0.05,{ }^{* *} p<0.01,{ }^{* * *} p<0.001$. 
characterized as $\mathrm{DAPI}^{+} / \mathrm{CK}^{+} / \mathrm{CD}^{-} 5^{-}$with cellular diameter falling in the range of $13-50 \mu \mathrm{m}$, which was technically due to the contamination of normal epithelial cells leaking into vacuum tubes during blood draw. Moreover, we showed that the number of $\mathrm{DAPI}^{+} / \mathrm{CK}^{+} / \mathrm{CD} 45^{-} \mathrm{CTCs}$ was associated with the clinical stages of RCC, with 1.2-fold more CTCs present in late-stage (III and IV) patient blood compared to those with early-stage (I and II) disease (Figure 5B and Table 4). By stratifying CTCs by Vimentin expression, we further demonstrated a significant correlation of $\mathrm{DAPI}^{+} / \mathrm{CK}^{+} / \mathrm{CD} 45$ - $/ \mathrm{Vimentin}^{+} \mathrm{CTC}$ number with clinical stages (I-IV) in the RCC patient cohort (Figure 5C and Table 4), suggesting that the mesenchymal status of CTCs could serve as a potential prognostic factor for RCC patients. In conclusion, we showed that the numbers of RCC CTCs captured from peripheral blood by our CA9-/CD147-based enrichment methods were well associated with the disease progression of RCC patients.

\section{DISCUSSION}

The detection of CTCs in genitourinary cancers, in particular prostate cancer and bladder cancer, has been widely investigated [4, 34]. In contrast, CTC research in RCC has shown little progress, which is due in large part to the lack of appropriate surface markers that can be used as capture antigens [35]. Currently, EpCAM is the major molecule serving as the capture antigen for CTC research reported in the literature [36-38]. EpCAM is an epithelial cell-specific marker which is highly expressed in breast cancer, prostate cancer and colon cancer but not in RCC (Figure 1) [39-41]. It is widely used as a CTCcapture antigen in many platforms, such as the CellSearch, microchip, microvortex-generating herringbone-chip, flow cytometry, magnetic sweeper and microfluidic devices [2, 42-49]. However, a growing body of research has indicated that EpCAM fails to recognize CTCs that are
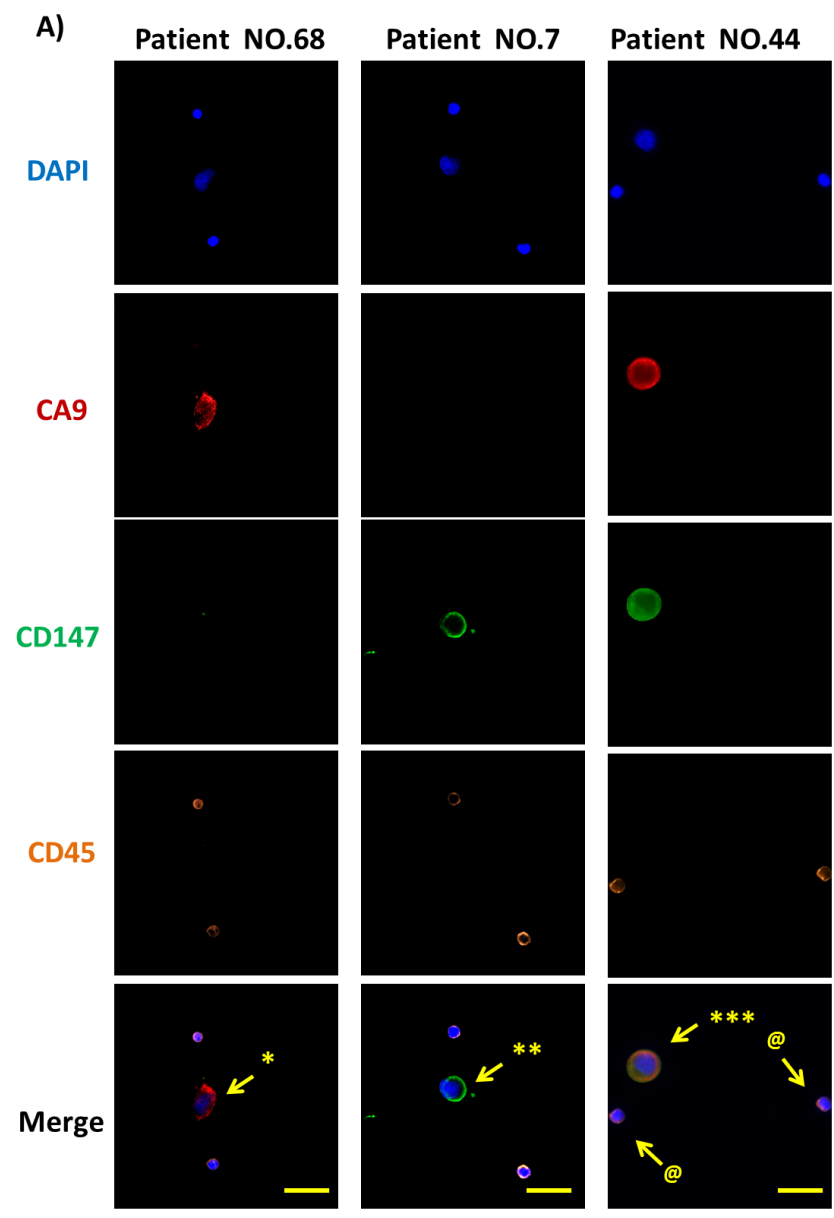

B)
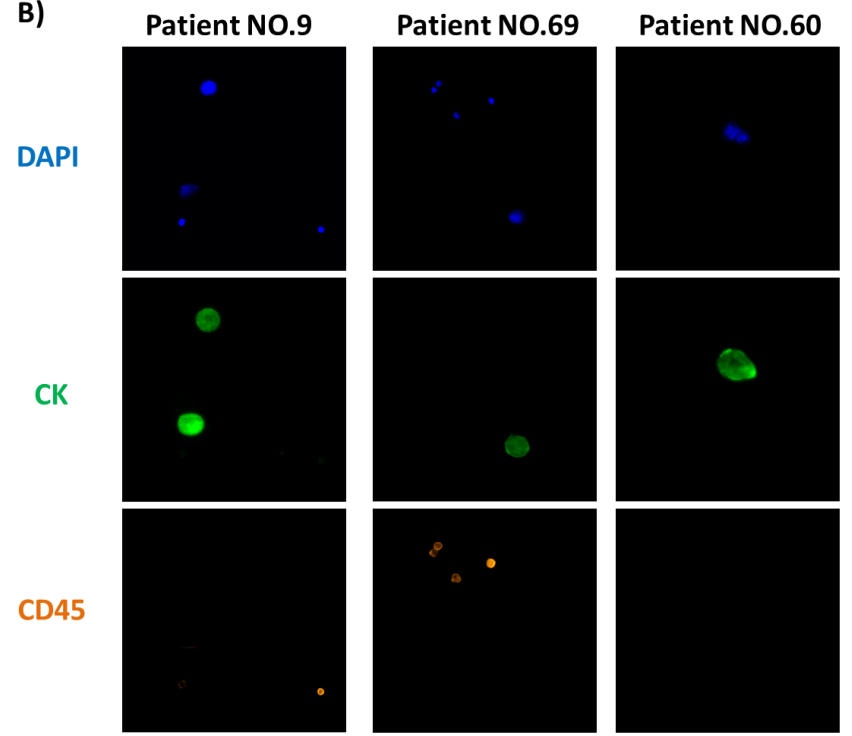

CD45
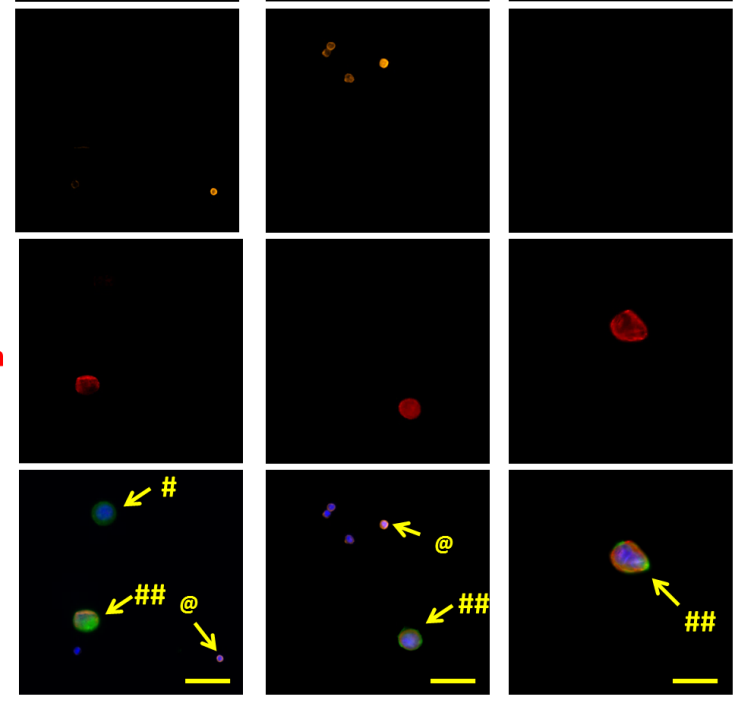

Figure 4: Immunofluorescence microscopic characterization of CTCs. A. DAPI (blue), anti-CA9 (red), anti-CD147 (green) and anti-CD45 (orange) antibodies were used to stain nuclei, CA9, CD147 and WBCs, respectively. Images from 3 representative patient samples (No. 68, 7 and 44) are shown. ${ }^{*} \mathrm{DAPI}^{+} / \mathrm{CA}^{+} / \mathrm{CD}^{-} 5^{-} \mathrm{CTCs}, * * \mathrm{DAPI}^{+} / \mathrm{CD} 147^{+} / \mathrm{CD} 45^{-} \mathrm{CTCs},{ }^{*} * \mathrm{DAPI}^{+} / \mathrm{CA}^{+} / \mathrm{CD} \mathrm{C}^{+} / \mathrm{CD}^{+} 5^{-}$ CTCs, and @ DAPI ${ }^{+} / \mathrm{CD}^{+} 5^{+}$WBCs. Original magnification, 400×; scale bars: $50 \mu \mathrm{m}$. B. DAPI (blue), anti-pan CK (green), anti-CD45 (orange) and anti-Vimentin (red) antibodies were used to stain nuclei, epithelial cells, WBCs and mesenchymal composition of CTCs, respectively. Images from 3 representative patient samples (No. 9, 69 and 60) are shown. \# $\mathrm{DAPI}^{+} / \mathrm{CK}^{+} / \mathrm{CD}^{-} / 5^{-} \mathrm{Vimentin}^{-} \mathrm{CTCs}$, \#\# DAPI ${ }^{+}$ $\mathrm{CK}^{+} / \mathrm{CD} 45 /$ Vimentin $^{+} \mathrm{CTCs}$, and @ DAPI $/$ CD45 WBCs. Original magnification, 400×; scale bars: $50 \mu \mathrm{m}$. 
Table 3: Numbers of $\mathrm{CA}^{+}$and/or CD147 ${ }^{+} \mathrm{CTCs}$ in $2 \mathrm{~mL}$ blood of select patients from the RCC patient cohort

\begin{tabular}{|c|c|c|c|c|c|c|}
\hline Patient No. & Stage & $\begin{array}{l}\text { Cell No. }\left(\mathrm{DAPI}^{+} /\right. \\
\text {CD45) }\end{array}$ & $\begin{array}{l}\text { Cell No. }\left(\mathrm{DAPI} \mathrm{I}^{+} / \mathrm{CD}_{45} / /\right. \\
\mathrm{CA9}^{+} \text {and/or CD147 }{ }^{+} \text {) }\end{array}$ & $\begin{array}{l}\%\left(\text { (DAPI }^{+} / \mathrm{CD}^{\circ} / \mathrm{CA9}^{+}\right. \\
\left.\text {and } / \text { or } \mathrm{CA} 147^{+}\right)\end{array}$ & $\begin{array}{l}\text { IHC score } \\
\text { (CA9) }\end{array}$ & $\begin{array}{l}\text { IHC score } \\
\text { (CD147) }\end{array}$ \\
\hline 1 & I & 11 & 9 & 82 & 12 & 3 \\
\hline 2 & I & 16 & 14 & 88 & 9 & 2 \\
\hline 4 & I & 20 & 18 & 90 & 6 & 9 \\
\hline 6 & I & 9 & 9 & 100 & 9 & 0 \\
\hline 8 & I & 25 & 20 & 80 & 8 & 12 \\
\hline 9 & I & 15 & 14 & 93 & 9 & 1 \\
\hline 14 & I & 28 & 23 & 82 & 9 & 6 \\
\hline 15 & I & 6 & 5 & 83 & 8 & 9 \\
\hline 16 & I & 11 & 9 & 82 & 12 & 1 \\
\hline 19 & I & 9 & 8 & 89 & 6 & 3 \\
\hline 20 & I & 25 & 23 & 92 & 12 & 3 \\
\hline 22 & I & 2 & 0 & 0 & 3 & 1 \\
\hline 25 & I & 16 & 13 & 81 & 9 & 4 \\
\hline 27 & I & 5 & 0 & 0 & 0 & 4 \\
\hline 29 & I & 13 & 10 & 77 & 9 & 8 \\
\hline 31 & II & 11 & 9 & 82 & 3 & 3 \\
\hline 34 & II & 21 & 19 & 90 & 9 & 6 \\
\hline 35 & II & 16 & 13 & 81 & 12 & 3 \\
\hline 39 & II & 17 & 15 & 88 & 9 & 3 \\
\hline 41 & II & 11 & 9 & 82 & 1 & 8 \\
\hline 43 & II & 28 & 19 & 68 & 4 & 4 \\
\hline 44 & II & 21 & 15 & 71 & 3 & 12 \\
\hline 45 & II & 17 & 14 & 82 & 9 & 8 \\
\hline 49 & III & 23 & 19 & 83 & 9 & 4 \\
\hline 51 & III & 16 & 13 & 81 & 12 & 3 \\
\hline 55 & III & 20 & 19 & 95 & 8 & 4 \\
\hline 59 & III & 25 & 18 & 72 & 2 & 9 \\
\hline 60 & III & 17 & 12 & 71 & 4 & 6 \\
\hline 61 & III & 21 & 17 & 81 & 3 & 9 \\
\hline 62 & III & 19 & 16 & 84 & 9 & 8 \\
\hline 63 & III & 34 & 33 & 97 & 6 & 6 \\
\hline 67 & IV & 12 & 11 & 92 & 9 & 4 \\
\hline 70 & IV & 8 & 7 & 88 & 8 & 9 \\
\hline
\end{tabular}

deficient in epithelial features, leading to low capture efficiency in such circumstances [7].

In this study, we proposed to substitute EpCAM with two cell surface markers, CA9 and CD147, for capturing RCC CTCs in peripheral blood. CA9 is a tumor hypoxia marker widely expressed in various types of human cancer [50-52]. High expression of CA9 in tumors is associated with increased aggressiveness and poor prognosis [53]. Specifically in RCC, CA9 is strongly expressed on the cell membrane [54] and associated with the histological 
subtype of specimens, with higher expression in CCRCC than in other RCC subtypes [17]. CD147 has also long been implicated in cancer development and metastasis with a close association with lymph node metastasis by enhancing EMT cell invasion through activation of the MAPK/ERK pathway [55]. CD147 expression is positively correlated with TNM stage and poor prognosis in RCC, with particularly high expression in advanced RCC that display higher T stage and shorter survival time $[21,56,57]$. Our findings on the prevalent expression of both CA9 and CD147 in our RCC patient cohort are consistent with previous reports from other groups (Figure 1 and Table 2). Although the idea of using CA9 and CD147 to attract CTCs is new, the characteristics of these molecules along with their high expression in RCC suggest their potential use as RCC CTC-capture antigens $[53,58,59]$, which is supported by our findings that the combined use of CA9 and CD147 as capture antigens retrieved CTCs from both $\mathrm{CTC}$-mimicking renal cancer cells as well as RCC patient blood with significantly improved capture efficiency compared to the EpCAMbased capture method (Figure 3).

The clinical value of CTCs has been extensively explored in a spectrum of cancers in recent years [2]. As reported by Bluemke et al, the patient CTC count was an independent prognostic factor correlating with lymph node invasion in RCC [60]. In another study, Seideman et al succeeded in capturing at least one CTC from 11 out of 12 RCC patients by the CellSearch system, but the CTC count failed to correlate with pathologic outcomes because of the insufficient number of patients studied [61]. In the present study, we were able to use the NanoVelcro platform in combination with the CA9-/CD147-based enrichment method to isolate CTCs from 72 out of 76 (94.7\%) RCC patients. Our new CTC-capture system exhibited significantly higher RCC CTC-capture efficiency than other approaches previously reported elsewhere. Our results further demonstrated the potential prognostic value of captured CTCs by both CTC counts and CTC molecular marker expression (Figure 5 and Table 4).
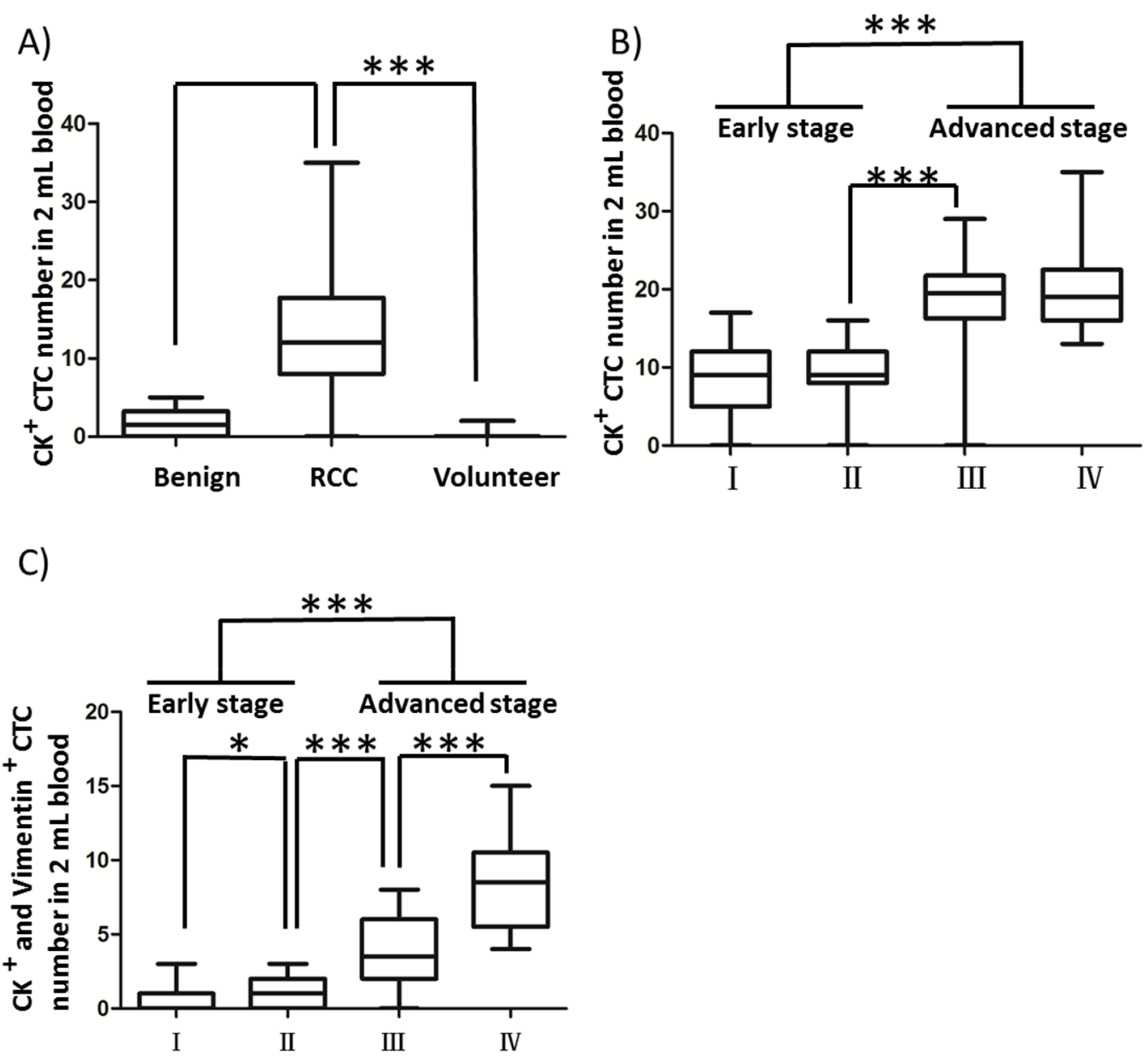

Figure 5: Correlation of CTC counts and CTC expression status of Vimentin with clinical indices in RCC patients. A. Comparison of $\mathrm{CK}^{+} \mathrm{CTC}$ counts in $2 \mathrm{~mL}$ peripheral blood from healthy volunteers, benign and RCC patients. Blood draw was conducted at the first visit for all registrants prior to surgery. $\mathbf{B}, \mathbf{C}$. Comparisons of numbers of $\mathrm{CK}^{+} / \mathrm{CD}^{-} 5^{-}$(B) and $\mathrm{CK}^{+} / \mathrm{CD}^{-} / 5^{-} \mathrm{Vimentin}^{+}(\mathrm{C}) \mathrm{CTCs}^{\mathrm{C}}$ captured in $2 \mathrm{~mL}$ blood from RCC patients across 4 different clinical stages. * $p<0.05, * * p<0.01,{ }^{* * *} p<0.001$. 
Table 4: Numbers of $\mathrm{CK}^{+}$and $\mathrm{CK}^{+} /$Vimentin ${ }^{+}$CTCs in $2 \mathrm{~mL}$ patient blood of the RCC patient cohort

\begin{tabular}{lcccc}
\hline Numbers & I & II & III & IV \\
\hline $\mathrm{CK}^{+}$ & $8.76 \pm 4.11$ & $9.32 \pm 3.64$ & $18.56 \pm 5.96$ & $20.42 \pm 5.97$ \\
$\mathrm{CK}^{+} /$Vimentin $^{+}$ & $0.55 \pm 0.77$ & $1.11 \pm 1.02$ & $3.81 \pm 2.27$ & $8.5 \pm 3.15$ \\
\hline
\end{tabular}

In addition to $\mathrm{CK}$, the gold standard marker defining epithelial CTCs, emerging studies have characterized CTCs with different molecular markers to monitor diverse cellular events that CTCs undergo in phenotypic changes [62]. A transition of adherent epithelial cells to a migratory mesenchymal state has been implicated in tumor metastasis and chemoresistance in preclinical models of multiple cancers [63-66]. Recent studies have also characterized EMT in CTC platforms from breast cancer patients and revealed dynamic changes in the epithelial and mesenchymal composition in CTCs. One intriguing finding was that mesenchymal cells were highly enriched in CTCs, which was associated with disease progression [67]. In line with these reports, we demonstrated the expression of Vimentin, a mesenchymal marker, in clinical RCC samples by IHC (data not shown) as well as in CTCs captured from peripheral blood (Figure 4). Moreover, we showed that the CTC expression of Vimentin was capable of stratifying clinical stages in our RCC cohort, providing a more stringent correlation of CTC number with disease progression than standard CTC enumeration methods (Figure 5 and Table 4). Given the growing interest in CTC research going beyond CTC counts, further molecular characterization of CTCs merits more attention, which would benefit from the ongoing development of improved capture platforms, such as the NanoVelcro system, aiming eventually for the noninvasive real-time monitoring of molecular changes in a "liquid biopsy" to allow clinicians to execute individually tailored treatment strategies.

In summary, we successfully developed a set of RCC CTC-capture antigens combining the use of cell surface markers CA9 and CD147 to capture CTCs in RCC patients. We showed for the first time that this enrichment strategy in combination with the NanoVelcro chip system dramatically improved the CTC-capture efficiency in RCC compared to the conventional EpCAMbased approach. Importantly, we demonstrated the clinical association of CTC number and Vimentin expression status in CTCs with RCC disease progression, including pathologic feature and clinical stage, which suggests the prognostic value of CTCs in RCC. Together, these studies provide new insights into developing cancer type-specific capture antigens for CTC isolation with improved efficacy, making CTCs a valuable addition to the armamentarium for cancer detection, prognosis and treatment.

\section{MATERIALS AND METHODS}

\section{Ethics statement}

Written informed consents were obtained from all patients. All data used in this study have been anonymized. This study was approved by the Ethics Committee (IRB) of Xijing Hospital (Xi'an, Shaanxi, China) (see Table 1 for detailed patient information) and performed in accordance with relevant Chinese regulations and the Declaration of Helsinki [68].

\section{Patients}

A total of 76 RCC patients, together with 10 benign renal patients, including angiomyolipoma, renal adenoma and fibroma, and 15 healthy volunteers were consecutively recruited from Xijing Hospital. All RCC patients $(n=76)$ were staged and grouped according to the 2010 American Joint Committee on Cancer TNM classification for RCC [69]. The clinical and histopathologic characteristics of the patients enrolled in this cohort are described in Tables 1 and 2 .

\section{NanoVelcro chip fabrication}

The NanoVelcro chips were fabricated following the well-established method reported by Wang et al [70]. The NanoVelcro chip is composed of three parts: (i) a patterned silicon nanowire (SiNW) substrate coated with streptavidin, (ii) an overlaid polydimethylsiloxane (PDMS) chaotic mixer, and (iii) a home-machined holder set to sandwich a well-aligned PDMS mixer chip with the SiNW substrate.

\section{CTC capture from patient blood samples}

For each participant, a total volume of $2 \mathrm{~mL}$ peripheral blood was collected using an EDTAcontaining vacutainer tube. The blood was first treated with lymphocyte separation medium (Dingguo, Beijing, China) to remove red blood cells. Mono-nucleated cells were rinsed with PBS and then standard culture medium after centrifuging at $600 \mathrm{~g}$ for 10 minutes. The supernatant was discarded and the cell pellet was re-suspended in $200 \mu \mathrm{L} 2 \%$ donkey serum. Before loading the sample, the streptavidin-coated $(1 \mathrm{mg} / \mathrm{mL}$, Life Technologies, Carlsbad, USA) NanoVelcro chip was modified with anti- 
CA9 $(0.1 \mu \mathrm{g} / \mathrm{mL}, \mathrm{BAF} 2188, \mathrm{R} \& \mathrm{D}$ Systems, Minneapolis, USA) and anti-CD147 (0.1 $\mu \mathrm{g} / \mathrm{mL}$, BAF972, R\&D Systems) antibodies by loading antibody solution into the channel using a syringe pump (KDS 200, KD Scientific Inc., Boston, USA). Prior to sample injection, the channel underwent PBS wash for multiple times to remove free antibodies. Afterwards, the prepared cell suspension was loaded at a $0.5 \mathrm{~mL} / \mathrm{h}$ flow rate. Finally, the NanoVelcro chip was loaded with $2 \%$ paraformaldehyde (PFA) for CTC fixation for further analysis.

\section{IHC analysis of tumor specimens}

In this study, we obtained 70 surgical tissue samples from the 76 registered RCC patients. Paraneoplastic normal renal tissues were used as negative control. Formalin-fixed paraffin-embedded samples were prepared as $4 \mathrm{~mm}$-thick sections and subjected to IHC staining using our previously published protocol [71]. After being blocked with $10 \%(\mathrm{v} / \mathrm{v})$ goat serum for 30 minutes, slides were immersed in anti-EpCAM antibody (dilution 1:200; ZSGB, Beijing, China), anti-CA9 antibody (dilution 1:200; Santa Cruz Biotechnology, Santa Cruz, USA), or anti-CD147 antibody (dilution 1:200; ZSGB) diluted in PBS containing $1 \%(\mathrm{w} / \mathrm{v})$ bovine serum albumin (BSA) at $4^{\circ} \mathrm{C}$ overnight in a moist chamber. After being treated with corresponding secondary antibodies for 30 minutes, the slides were stained with diaminobenzidine (DAB, ZSGB) and counterstained with hematoxylin. A light microscope (Olympus BX51, Olympus, Japan) was used to capture images with a DP70 digital camera.

IHC staining in each sample was scored by a semiquantitative method by taking into account both staining intensity (I) and quantity for the proportion of tumor cells stained (q) to obtain a final score defined as the product of $\mathrm{I} \times \mathrm{q}$. The scoring system for I was: 0 , negative; 1 , weak; 2 , moderate; 3 strong staining. The scoring system for q was: $0,<1 \% ; 1,2-25 \% ; 2,26-50 \% ; 3,51-75 \%$; 4, 76-100\%. Finally, IHC scores ranging from 0 to 12 were obtained and further categorized into two groups, negative (-, $0-2)$ and positive (+, 3-12), based on different scores. All scoring was performed by two pathologists independently who had no prior information on the pathologic status of specimens to be assessed.

\section{Cell culture}

Human renal cancer Caki-1 and Caki-2 cell lines were obtained from the American Type Culture Collection (ATCC, Manassas, USA). Cells were cultured in RPMI1640 (Life Technologies, Carlsbad, USA) supplemented with 5\% fetal bovine serum (FBS, Life Technologies), penicillin (100 unit $/ \mathrm{mL}$ ), and streptomycin $(100 \mu \mathrm{g} / \mathrm{mL})$ at $37^{\circ} \mathrm{C}$ in a humidified atmosphere with $5 \% \mathrm{CO}_{2}$. Before spiking, cells were detached with trypsin (Life Technologies), washed and suspended in PBS.

\section{Immunocytochemistry and immunofluorescence analysis of CTCs}

A $200 \mu \mathrm{L}$ primary antibody cocktail consisting of $1 \mu \mathrm{L}$ rabbit anti-pan CK antibody (ab9377, Abcam, Cambridge, UK), $2 \mu \mathrm{L}$ mouse anti-CD45 (ab30470, Abcam), $2 \mu \mathrm{L}$ chicken anti-Vimentin antibody (ab24525,

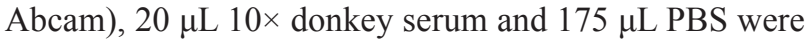
added into the CTC fixation substrate and incubated at $4{ }^{\circ} \mathrm{C}$ overnight. To confirm the expression of CA9 and CD147 in captured CTCs, alternative primary antibody cocktail by replacing aforementioned anti-pan CK and anti-Vimentin antibodies with anti-CA9 and anti-CD147 antibodies as described in IHC analysis of human RCC samples was used. The CTC fixation substrates were then washed with PBS twice, and a $200 \mu \mathrm{L}$ secondary antibody cocktail consisting of $4 \mu \mathrm{L}$ Alexa Fluor 488 conjugated donkey anti-rabbit antibody (A21206, Life Technologies), $4 \mu \mathrm{L}$ Alexa Fluor 555 conjugated donkey anti-mouse antibody (A31570, Life Technologies), $4 \mu \mathrm{L}$ Alexa Fluor conjugated 647 goat anti-chicken IgG antibody (ab150175, Abcam), $20 \mu \mathrm{L} \mathrm{10 \times} \mathrm{donkey} \mathrm{serum} \mathrm{and} 168$ $\mu \mathrm{L}$ PBS were added into the CTC fixation substrate and incubated at room temperature in the dark for 1 hour. After applying DAPI (1:1000, Life Technologies) for nuclear staining, the sections were mounted with a cover slip for fluorescence microscopy. Images were obtained by a light microscope equipped with NIS-Element imaging software (ECLIPSE 90i, Nikon, Japan). In brief, the whole area of the NanoVelcro chip was first scanned at $40 \times$ magnification, and the images were analyzed for potential cells identified in $400 \times$ magnification. The final enumerations were based on the criteria of $\mathrm{DAPI}^{+} / \mathrm{CK}^{+} /$ $\mathrm{CD}^{2} 5^{-}, 13 \mu \mathrm{m}<$ cellular diameter $<50 \mu \mathrm{m}$, and nuclear/ cytoplasmic ratio $>50 \%$.

\section{Statistical analysis}

Statistical analysis was performed with SPSS 17.0 software (SPSS Inc., Armonk, USA). Statistical comparisons were analyzed using Student's t test, and $p$ values less than 0.05 were considered to be statistically significant.

\section{ACKNOWLEDGMENTS}

We are grateful to Gina Chia-Yi Chu (Uro-Oncology Research Program, Department of Medicine, Samuel Oschin Comprehensive Cancer Institute, Cedars-Sinai Medical Center) for technical assistance. We also thank Gary Mawyer for editorial assistance. This work was supported by grants from the Program of International Science and Technology Cooperation of China (No. 2011DFA33110) and National Natural Science Foundation of China (No. 21402211, 81572529 and 30271302). 


\section{CONFLICTS OF INTEREST}

All authors disclose no conflicts of interest in the preparation of this manuscript.

\section{REFERENCES}

1. Plaks V, Koopman CD, Werb Z. Circulating tumor cells. Science. 2013; 341.

2. Cristofanilli M, Budd GT, Ellis MJ, Stopeck A, Matera J, Miller MC, Reuben JM, Doyle GV, Allard WJ, Terstappen LWMM, Hayes DF. Circulating tumor cells, disease progression, and survival in metastatic breast cancer. The New England journal of medicine. 2004; 351:781-791.

3. Wallwiener M, Riethdorf S, Hartkopf D, Modugno C, Nees J, Madhavan D, Sprick MR, Schott S, Domschke C, Baccelli I, Schoenfisch B, Burwinkel B, Marme F, et al. Serial enumeration of circulating tumor cells predicts treatment response and prognosis in metastatic breast cancer: a prospective study in 393 patients. BMC cancer. 2014; 14.

4. Thalgott M, Rack B, Eiber M, Souvatzoglou M, Heck MM, Kronester C, Andergassen U, Kehl V, Krause BJ, Gschwend JE, Retz M, Nawroth R. Categorical versus continuous circulating tumor cell enumeration as early surrogate marker for therapy response and prognosis during docetaxel therapy in metastatic prostate cancer patients. BMC cancer. 2015; 15:458.

5. Schulze K, Gasch C, Staufer K, Nashan B, Lohse AW, Pantel K, Riethdorf S, Wege H. Presence of EpCAMpositive circulating tumor cells as biomarker for systemic disease strongly correlates to survival in patients with hepatocellular carcinoma. International Journal of Cancer. 2013; 133:2165-2171.

6. Riethdorf S, Fritsche H, Mueller V, Rau T, Schindibeck C, Rack B, Janni W, Coith C, Beck K, Jaenicke F, Jackson $\mathrm{S}$, Gornet T, Cristofanilli M, et al. Detection of circulating tumor cells in peripheral blood of patients with metastatic breast cancer: A validation study of the CellSearch system. Clinical Cancer Research. 2007; 13:920-928.

7. Gorges TM, Tinhofer I, Drosch M, Roese L, Zollner TM, Krahn T, von Ahsen O. Circulating tumour cells escape from EpCAM-based detection due to epithelial-tomesenchymal transition. BMC cancer. 2012; 12.

8. de Wit $\mathrm{S}$, van Dalum G, Lenferink AT, Tibbe AG, Hiltermann JT, Groen HJ, van Rijn C, Terstappen LW. EpCAM+ and EpCAM-circulating tumor cells in metastatic lung cancer. Cancer research. 2015; 75:377-377.

9. Königsberg R, Obermayr E, Bises G, Pfeiler G, Gneist M, Wrba F, de Santis M, Zeillinger R, Hudec M, Dittrich C. Detection of EpCAM positive and negative circulating tumor cells in metastatic breast cancer patients. Acta oncologica. 2011; 50:700-710.
10. Onstenk W, Kraan J, Mostert B, Timmermans MM, Charehbili A, Smit VT, Kroep JR, Nortier JW, van de Ven S, Heijns JB. Improved Circulating Tumor Cell Detection by a Combined EpCAM and MCAM CellSearch Enrichment Approach in Patients with Breast Cancer Undergoing Neoadjuvant Chemotherapy. Molecular cancer therapeutics. 2015; 14:821-827.

11. Siegel RL, Miller KD, Jemal A. Cancer statistics, 2015. CA Cancer J Clin. 2015; 65:5-29.

12. Fizazi K, Greco F, Pavlidis N, Daugaard G, Oien K, Pentheroudakis G. Cancers of unknown primary site: ESMO Clinical Practice Guidelines for diagnosis, treatment and follow-up. Annals of Oncology. 2015; 26:v133-v138.

13. Rossi E, Fassan M, Aieta M, Zilio F, Celadin R, Borin M, Grassi A, Troiani L, Basso U, Barile C, Sava T, Lanza C, Miatello L, et al. Dynamic changes of live/apoptotic circulating tumour cells as predictive marker of response to sunitinib in metastatic renal cancer. British journal of cancer. 2012; 107:1286-1294.

14. Campbell L, Gumbleton M, Griffiths DF. Caveolin-1 overexpression predicts poor disease-free survival of patients with clinically confined renal cell carcinoma. British journal of cancer. 2003; 89:1909-1913.

15. Lam JS, Klatte T, Kim HL, Patard JJ, Breda A, Zisman A, Pantuck AJ, Figlin RA. Prognostic factors and selection for clinical studies of patients with kidney cancer. Critical reviews in oncology/hematology. 2008; 65:235-262.

16. Cairns P. Renal cell carcinoma. Cancer biomarkers. 2010; 9:461-473.

17. Takacova M, Bartosova M, Skvarkova L, Zatovicova M, Vidlickova I, Csaderova L, Barathova M, Breza J, Jr., Bujdak P, Pastorek J, Breza J, Sr., Pastorekova S. Carbonic anhydrase IX is a clinically significant tissue and serum biomarker associated with renal cell carcinoma. Oncology letters. 2013; 5:191-197.

18. Davidson B, Goldberg I, Berner A, Kristensen GB, Reich R. EMMPRIN (extracellular matrix metalloproteinase inducer) is a novel marker of poor outcome in serous ovarian carcinoma. Clinical \& experimental metastasis. 2003; 20:161-169.

19. Als AB, Dyrskjot L, von der Maase H, Koed K, Mansilla F, Toldbod HE, Jensen JL, Ulhoi BP, Sengelov L, Jensen KM, Orntoft TF. Emmprin and survivin predict response and survival following cisplatin-containing chemotherapy in patients with advanced bladder cancer. Clinical Cancer Research. 2007; 13:4407-4414.

20. Tan H, Ye K, Wang Z, Tang H. CD147 expression as a significant prognostic factor in differentiated thyroid carcinoma. Translational Research. 2008; 152:143-149.

21. Liang YX, He HC, Han ZD, Bi XC, Dai QS, Ye YK, Qin WJ, Zeng GH, Zhu G, Xu CL, Zhong WD. CD147 and VEGF expression in advanced renal cell carcinoma and their prognostic value. Cancer investigation. 2009; 27:788-793. 
22. Network CGAR. Comprehensive molecular characterization of clear cell renal cell carcinoma. Nature. 2013; 499:43-49.

23. Weissenstein U, Schumann A, Reif M, Link S, ToffolSchmidt UD, Heusser P. Detection of circulating tumor cells in blood of metastatic breast cancer patients using a combination of cytokeratin and EpCAM antibodies. BMC cancer. 2012; 12.

24. Sangoi AR, Fujiwara M, West RB, Montgomery KD, Bonventre JV, Higgins JP, Rouse RV, Gokden N, McKenney JK. Immunohistochemical Distinction of Primary Adrenal Cortical Lesions From Metastatic Clear Cell Renal Cell Carcinoma: A Study of 248 Cases. American Journal Of Surgical Pathology. 2011; 35:678-686.

25. Vasudev NS, Selby PJ, Banks RE. Renal cancer biomarkers: the promise of personalized care. BMC medicine. 2012; 10:112.

26. Wang L, Asghar W, Demirci U, Wan Y. Nanostructured substrates for isolation of circulating tumor cells. Nano Today. 2013; 8:374-387.

27. Lu YT, Zhao L, Shen Q, Garcia MA, Wu D, Hou S, Song M, Xu X, Ouyang WH, Ouyang WW, Lichterman J, Luo Z, Xuan X, et al. NanoVelcro Chip for CTC enumeration in prostate cancer patients. Methods. 2013; 64:144-152.

28. Yoon HJ, Kozminsky M, Nagrath S. Emerging Role of Nanomaterials in Circulating Tumor Cell Isolation and Analysis. ACS nano. 2014; 8:1995-2017.

29. Hou S, Zhao L, Shen Q, Yu J, Ng C, Kong X, Wu D, Song M, Shi X, Xu X, OuYang W-H, He R, Zhao X-Z, et al. Polymer Nanofiber-Embedded Microchips for Detection, Isolation, and Molecular Analysis of Single Circulating Melanoma Cells. Angew Chem Int Ed Engl. 2013; 52:3379-3383.

30. Vuoriluoto K, Haugen H, Kiviluoto S, Mpindi J, Nevo J, Gjerdrum C, Tiron C, Lorens J, Ivaska J. Vimentin regulates EMT induction by Slug and oncogenic $\mathrm{H}$-Ras and migration by governing Axl expression in breast cancer. Oncogene. 2011; 30:1436-1448.

31. Satelli A, Li S. Vimentin in cancer and its potential as a molecular target for cancer therapy. Cellular and Molecular Life Sciences. 2011; 68:3033-3046.

32. Kokkinos MI, Wafai R, Wong MK, Newgreen DF, Thompson EW, Waltham M. Vimentin and epithelialmesenchymal transition in human breast cancerobservations in vitro and in vivo. Cells Tissues Organs. 2007; 185:191-203.

33. Otsuki S, Inokuchi M, Enjoji M, Ishikawa T, Takagi Y, Kato K, Yamada H, Kojima K, Sugihara K. Vimentin expression is associated with decreased survival in gastric cancer. Oncology reports. 2011; 25:1235-1242.

34. Ju M, Kao GD, Steinmetz D, Chandrasekaran S, Keefe SM, Guzzo TJ, Christodouleas JP, Hahn SM, Dorsey JF. Application of a telomerase-based circulating tumor cell (CTC) assay in bladder cancer patients receiving postoperative radiation therapy: a case study. Cancer biology \& therapy. 2014; 15:683-687.
35. Small AC, Gong Y, Oh WK, Hall SJ, van Rijn CJM, Galsky MD. The Emerging Role of Circulating Tumor Cell Detection in Genitourinary Cancer. Journal Of Urology. 2012; 188:21-26.

36. George TJ, Sheng W, Varillas JI, Liu C, Fan ZH. Identification of low number circulating tumor cells (CTCs) for cancer treatment monitoring. Cancer research. 2015; 75:1607-1607.

37. Myung JH, Tam KA, Park Sj, Cha A, Hong S. Recent advances in nanotechnology-based detection and separation of circulating tumor cells. Wiley Interdisciplinary Reviews: Nanomedicine and Nanobiotechnology. 2015.

38. de Wit S, van Dalum G, Lenferink AT, Tibbe AG, Hiltermann TJN, Groen HJ, van Rijn CJ, Terstappen LW. The detection of EpCAM+ and EpCAM-circulating tumor cells. Scientific reports. 2015; 5.

39. Spizzo G, Fong D, Wurm M, Ensinger C, Obrist P, Hofer C, Mazzoleni G, Gastl G, Went P. EpCAM expression in primary tumour tissues and metastases: an immunohistochemical analysis. Journal of clinical pathology. 2011; 64:415-420.

40. Baeuerle PA, Gires O. EpCAM (CD326) finding its role in cancer. British journal of cancer. 2007; 96:417-423.

41. van der Gun BTF, Melchers LJ, Ruiters MHJ, de Leij LFMH, McLaughlin PMJ, Rots MG. EpCAM in carcinogenesis: the good, the bad or the ugly. Carcinogenesis. 2010; 31:1913-1921.

42. Ozkumur E, Shah AM, Ciciliano JC, Emmink BL, Miyamoto DT, Brachtel E, Yu M, Chen P-i, Morgan B, Trautwein J, Kimura A, Sengupta S, Stott SL, et al. Inertial Focusing for Tumor Antigen-Dependent and -Independent Sorting of Rare Circulating Tumor Cells. Science Translational Medicine. $2013 ; 5$.

43. Nagrath S, Sequist LV, Maheswaran S, Bell DW, Irimia D, Ulkus L, Smith MR, Kwak EL, Digumarthy S, Muzikansky A, Ryan P, Balis UJ, Tompkins RG, et al. Isolation of rare circulating tumour cells in cancer patients by microchip technology. Nature. 2007; 450:1235-U1210.

44. Stott SL, Hsu C-H, Tsukrov DI, Yu M, Miyamoto DT, Waltman BA, Rothenberg SM, Shah AM, Smas ME, Korir GK, Floyd FP, Jr., Gilman AJ, Lord JB, et al. Isolation of circulating tumor cells using a microvortex-generating herringbone-chip. Proceedings of the National Academy of Sciences of the United States of America. 2010; 107:18392-18397.

45. Talasaz AH, Powell AA, Huber DE, Berbee JG, Roh K-H, Yu W, Xiao W, Davis MM, Pease RF, Mindrinos MN, Jeffrey SS, Davis RW. Isolating highly enriched populations of circulating epithelial cells and other rare cells from blood using a magnetic sweeper device. Proceedings of the National Academy of Sciences of the United States of America. 2009; 106:3970-3975.

46. Kirby BJ, Jodari M, Loftus MS, Gakhar G, Pratt ED, Chanel-Vos C, Gleghorn JP, Santana SM, Liu H, Smith JP, Navarro VN, Tagawa ST, Bander NH, et al. Functional 
Characterization of Circulating Tumor Cells with a Prostate-Cancer-Specific Microfluidic Device. PloS one. 2012; 7.

47. Barradas AMC, Terstappen LWMM. Towards the Biological Understanding of CTC: Capture Technologies, Definitions and Potential to Create Metastasis. Cancers. 2013; 5:1619-1642.

48. Frithiof H, Welinder C, Larsson AM, Ryden L, Aaltonen K. A novel method for downstream characterization of breast cancer circulating tumor cells following CellSearch isolation. Journal of translational medicine. 2015; 13:126.

49. El-Heliebi A, Kroneis T, Zoehrer E, Haybaeck J, Fischereder K, Kampel-Kettner K, Zigeuner R, Pock H, Riedl R, Stauber R, Geigl JB, Huppertz B, Sedlmayr P, et al. Are morphological criteria sufficient for the identification of circulating tumor cells in renal cancer? Journal of translational medicine. 2013; 11:214.

50. Loncaster JA, Harris AL, Davidson SE, Logue JP, Hunter RD, Wycoff CC, Pastorek J, Ratcliffe PJ, Stratford IJ, West CM. Carbonic anhydrase (CA IX) expression, a potential new intrinsic marker of hypoxia: correlations with tumor oxygen measurements and prognosis in locally advanced carcinoma of the cervix. Cancer research. 2001; 61:6394-6399.

51. Swinson DEB, Jones JL, Richardson D, Wykoff C, Turley H, Pastorek J, Taub N, Harris AL, O'Byrne KJ. Carbonic anhydrase IX expression, a novel surrogate marker of tumor hypoxia, is associated with a poor prognosis in nonsmall-cell lung cancer. Journal of Clinical Oncology. 2003; 21:473-482.

52. Wykoff CC, Beasley NJ, Watson PH, Turner KJ, Pastorek J, Sibtain A, Wilson GD, Turley H, Talks KL, Maxwell PH, Pugh CW, Ratcliffe PJ, Harris AL. Hypoxia-inducible expression of tumor-associated carbonic anhydrases. Cancer research. 2000; 60:7075-7083.

53. Huang W-J, Jeng Y-M, Lai H-S, Fong I-U, Sheu F-YB, Lai P-L, Yuan R-H. Expression of Hypoxic Marker Carbonic Anhydrase IX Predicts Poor Prognosis in Resectable Hepatocellular Carcinoma. PloS one. 2015; 10.

54. Ilardi G, Zambrano N, Merolla F, Siano M, Varricchio S, Vecchione M, De Rosa G, Mascolo M, Staibano S. Histopathological Determinants of Tumor Resistance: A Special Look to the Immunohistochemical Expression of Carbonic Anhydrase IX in Human Cancers. Current Medicinal Chemistry. 2014; 21:1569-1582.

55. Xu T, Zhou M, Peng L, Kong S, Miao R, Shi Y, Sheng $\mathrm{H}, \mathrm{Li}$ L. Upregulation of CD147 promotes cell invasion, epithelial-to-mesenchymal transition and activates MAPK/ ERK signaling pathway in colorectal cancer. International Journal Of Clinical And Experimental Pathology. 2014; 7:7432-7441.

56. Tsai W-C, Sheu L-F, Nieh S, Yu C-P, Sun G-H, Lin Y-F, Chen A, Jin J-S. Association of EMMPRIN and fascin expression in renal cell carcinoma: correlation with clinicopathological parameters. World journal of urology. $2007 ; 25: 73-80$.

57. Xiong L, Edwards CK, III, Zhou L. The Biological Function and Clinical Utilization of CD147 in Human Diseases: A Review of the Current Scientific Literature. International journal of molecular sciences. 2014; 15:17411-17441.

58. Zhu P, Lu N, Shi Z-g, Zhou J, Wu Z-b, Yang Y, Ding J, Chen Z-n. CD147 overexpression on synoviocytes in rheumatoid arthritis enhances matrix metalloproteinase production and invasiveness of synoviocytes. Arthritis research \& therapy. 2006; 8:R44-R44.

59. Yang J-M, O'Neill P, Jin W, Foty R, Medina DJ, Xu Z, Lomas M, Arndt GM, Tang Y, Nakada M, Yan L, Hait WN. Extracellular matrix metalloproteinase inducer (CD147) confers resistance of breast cancer cells to Anoikis through inhibition of Bim. The Journal of biological chemistry. 2006; 281:9719-9727.

60. Bluemke $\mathrm{K}$, Bilkenroth $\mathrm{U}$, Meye A, Fuessel S, Lautenschlaeger C, Goebel S, Melchior A, Heynemann H, Fornara P, Taubert H. Detection of Circulating Tumor Cells in Peripheral Blood of Patients with Renal Cell Carcinoma Correlates with Prognosis. Cancer Epidemiology Biomarkers \& Prevention. 2009; 18:2190-2194.

61. Seideman CA, Herati AS, Pan S, Cho JS, Cinman N, Tai J, Liu E, Shi E, Vira M. Prognostic correlation of circulating tumor cells in the setting of urothelial and renal cell carcinoma. Journal Of Urology. 2009; 181:108-109.

62. Armstrong AJ, Marengo MS, Oltean S, Kemeny G, Bitting RL, Turnbull JD, Herold CI, Marcom PK, George DJ, Garcia-Blanco MA. Circulating Tumor Cells from Patients with Advanced Prostate and Breast Cancer Display Both Epithelial and Mesenchymal Markers. Molecular Cancer Research. 2011; 9:997-1007.

63. Tiwari N, Gheldof A, Tatari M, Christofori G. (2012). EMT as the ultimate survival mechanism of cancer cells. Seminars in cancer biology: Elsevier), pp. 194-207.

64. Asiedu MK, Ingle JN, Behrens MD, Radisky DC, Knutson KL. TGF $\beta / T N F \alpha$-mediated epithelial-mesenchymal transition generates breast cancer stem cells with a claudin-low phenotype. Cancer research. 2011; 71:4707-4719.

65. Foroni C, Broggini M, Generali D, Damia G. Epithelialmesenchymal transition and breast cancer: Role, molecular mechanisms and clinical impact. Cancer treatment reviews. 2012; 38:689-697.

66. Findlay VJ, Wang C, Watson DK, Camp ER. Epithelialto-mesenchymal transition and the cancer stem cell phenotype: insights from cancer biology with therapeutic implications for colorectal cancer. Cancer gene therapy. 2014; 21:181-187.

67. Yu M, Bardia A, Wittner BS, Stott SL, Smas ME, Ting DT, Isakoff SJ, Ciciliano JC, Wells MN, Shah AM, Concannon KF, Donaldson MC, Sequist LV, et al. Circulating Breast Tumor Cells Exhibit Dynamic Changes in Epithelial and Mesenchymal Composition. Science. 2013; 339:580-584. 
68. World Medical A. World Medical Association Declaration of Helsinki: ethical principles for medical research involving human subjects. JAMA. 2013; 310:2191-2194.

69. Ridge CA, Pua BB, Madoff DC. Epidemiology and staging of renal cell carcinoma. Seminars in interventional radiology. 2014; 31:3-8.

70. Wang S, Wang H, Jiao J, Chen KJ, Owens GE, Kamei $\mathrm{K}$, Sun J, Sherman DJ, Behrenbruch CP, Wu H, Tseng
HR. Three-dimensional nanostructured substrates toward efficient capture of circulating tumor cells. Angew Chem Int Ed Engl. 2009; 48:8970-8973.

71. Zhou J, Zhang L, Gu Y, Li K, Nie Y, Fan D, Feng Y. Dynamic expression of CEACAM7 in precursor lesions of gastric carcinoma and its prognostic value in combination with CEA. World Journal Of Surgical Oncology. 2011; 9. 